\title{
Myelin Formation during Development of the CNS Is Delayed in Matrix Metalloproteinase-9 and -12 Null Mice
}

\author{
Peter H. Larsen, ${ }^{1}$ Angelika Goncalves DaSilva, ${ }^{1}$ Katherine Conant, ${ }^{2}$ and V. Wee Yong ${ }^{1}$ \\ ${ }^{1}$ Hotchkiss Brain Institute and Department of Clinical Neurosciences, University of Calgary, Calgary, Alberta, Canada T2N 4N1, and ${ }^{2}$ Department of \\ Neurology, Johns Hopkins University, Baltimore, Maryland 21205
}

The matrix metalloproteinases (MMPs) are implicated in several activities within the nervous system. Although many functions of abnormally elevated MMPs are undesirable, the discrete expression of particular MMP members can have beneficial roles. We previously found that MMP-9 expressed locally around a demyelinating lesion of the spinal cord of adult mice facilitated remyelination. In the current study, we have addressed whether and how MMPs might be required for myelin formation in normal ontogeny. Using a probe for multiple MMPs and the developing mouse optic nerve, we found two members, MMP-9 and -12, to be upregulated during the period of myelin formation. These MMPs partake in myelinogenesis because myelination in the corpus callosum of MMP-9 and/or MMP-12 null mice was deficient from postnatal days 7 to 14 compared with that of wild-type mice. The deficient myelination was correlated with fewer mature oligodendrocytes, but similar precursor cell numbers, in MMP null animals compared with wild type. Because an important growth factor for oligodendrocyte maturation is insulin-like growth factor-1 (IGF-1), we addressed whether this was involved in the deficient myelination in MMP null mice. Indeed, the addition of IGF-1 normalized the lack of maturation of oligodendrocytes that occurred in cultures from MMP-12 null mice. Furthermore, we determined that IGF binding protein 6 (IGFBP-6), which sequesters IGF-1, was a substrate for MMP processing. Finally, we found IGFBP-6 levels to remain high in MMP-deficient mice. These results reveal a novel function for MMP-9 and -12 in developmental myelination likely through regulating IGF-1 bioavailability.

Key words: myelination; matrix metalloproteinase; oligodendrocyte; differentiation; IGF; development

\section{Introduction}

Myelin formation in the brain occurs predominantly after birth in well regulated steps (Skoff et al., 1976; Dangata and Kaufman, 1997). During this event, oligodendrocytes (OLs) mature and they extend processes to contact and enwrap axons. Myelin formation is critical for the proper function and survival of axons (Lappe-Siefke et al., 2003). Equally important is the recognition that the survival of OLs depends on their interactions with axons (Trapp et al., 1997). The loss of myelin thus results in disease, a common one of which is multiple sclerosis in which demyelination and concurrent axonal loss lead to significant disability. Thus, recognizing the factors that can promote myelin formation is of major importance for the well being of the CNS.

Matrix metalloproteinases (MMPs) are a group of proteolytic enzymes that are generally considered to be detrimental to the CNS. However, although the massive upregulation of MMPs in the CNS is associated with many neurological conditions (Yong et al., 2001), their discrete expression at particular disease phase may have important physiological or regenerative roles (Yong,

Received May 11, 2005; revised Dec. 20, 2005; accepted Jan. 15, 2006.

This work was supported by an operating grant from the Multiple Sclerosis Society of Canada. P.H.L. and A.G.D. were supported by studentships from the Multiple Sclerosis Society of Canada. V.W.Y. is a Canada Research Chair in Neuroimmunology.

Correspondence should be addressed to Dr. V. Wee Yong, University of Calgary, 3330 Hospital Drive, Calgary, Alberta, Canada T2N 4N1.E-mail: vyong@ucalgary.ca.

DOI:10.1523/JNEUROSCI.1880-05.2006

Copyright $\odot 2006$ Society for Neuroscience $\quad$ 0270-6474/06/262207-08\$15.00/0
2005). We were the first to demonstrate that MMP-9 (Uhm et al., 1998; Oh et al., 1999) and MMP-12 (Larsen and Yong, 2004) were produced by OLs in vitro to help regulate their extension of processes. Moreover, we found that, after a demyelinating lesion inflicted on the spinal cord of adult mice, MMP-9 promoted the maturation of OLs and remyelination by removing an inhibitory NG2 proteoglycan (Larsen et al., 2003). These studies indicate multiple roles for MMPs in OL biology in vitro and after injury to the CNS. Whether MMPs control myelination in development is unknown.

Many growth factors are involved in the normal development of myelin, and among these is insulin-like growth factor 1 (IGF-1) (D'Ercole et al., 2002). Myelin formation is enhanced developmentally in IGF-1 transgenic mice (Carson et al., 1993) and reduced in IGF-1-null mice (Ye et al., 2002). In animals with disrupted IGF-1 receptor signaling, remyelination is impaired after cuprizone-induced demyelination (Mason et al., 2003). The actions of IGF- 1 are tightly regulated by six high-affinity IGF binding proteins (IGFBPs), which sequester and reduce the bioavailability of IGF-1 (Pollak et al., 2004; Rosenzweig, 2004). Of relevance to myelination is IGFBP-6, because it is synthesized in the CNS, by astrocytes and OLs (Mewar and McMorris, 1997), and its decreasing levels in cultures coincide with increasing maturation of OLs (Kuhl et al., 2003). Furthermore, IGFBP-6 added exogenously to cultures led to a reduction in the survival of OL precursor cells (OPCs) and the expression of myelin proteins (Kuhl et al., 2003). Because IGFBPs are substrates for MMPs 
(Bunn and Fowlkes, 2003; Sadowski et al., 2003; Fowlkes et al., 2004; Miyamoto et al., 2004), a potential interaction between MMPs, IGFBPs, and myelination can be considered.

In this study, we investigated the expression and function of MMP members during developmental myelin formation in mice, and we have addressed whether their regulation of myelination involves the processing of IGFBPs to regulate IGF-1 bioavailability.

\section{Materials and Methods}

RNase protection assay. Multiprobe RNase protection assay (RPA) was performed to analyze simultaneously the expression of several MMP members during specific postnatal days from postnatal day 2 (P2) to P30. We used the optic nerve for RPA analyses, because this structure could be dissected out from animals of all ages without the contamination of other regions. The optic nerves were dissected and placed in Trizol for RNA extraction. Ten nerves were collected and pooled for each time point to get enough RNA for a single analysis. After RNA extraction, $15 \mu \mathrm{g}$ of total RNA was used for each sample. The mouse MMP multiprobe set was kindly provided by Dr. Iain Campbell (The Scripps Research Institute, La Jolla, CA) (Pagenstecher et al., 1998). RPA was performed as described previously (Larsen and Yong, 2004). In brief, RNA samples were hybridized to the radioactive $\left[\alpha-{ }^{33} \mathrm{P}\right] \mathrm{UTP}$-labeled antisense multiprobe set overnight at $56^{\circ} \mathrm{C}$. After $1.5 \mathrm{~h}$ digestion of unhybridized probe with an RNase A and T1 mix (PharMingen, San Diego, CA), the protected fragments were treated with proteinase $\mathrm{K}(10 \mu \mathrm{g} / \mathrm{ml})$ and extracted with phenol/chloroform. Samples were separated on a $6 \%$ polyacrylamide gel, analyzed by phosphor imaging (Molecular Dynamics, Amersham Biosciences, Piscataway, NJ), and normalized to a ribosomal housekeeping protein, RPL-32.

MMP-9 and MMP-12 null mice. MMP-9 null mice on the 129/SvEv background were obtained from Dr. Zena Werb (University of California, San Francisco, San Francisco, CA) (Vu et al., 1998), whereas MMP-12 null mice on the same background were from Dr. Steve Shapiro (Harvard Medical School, Boston, MA) (Shipley et al., 1996). These mice were bred in-house and their genotype and lack of MMP-9 or -12 enzymatic activity have been confirmed previously (Oh et al., 1999; Larsen and Yong, 2004). To generate MMP-9 and -12 double-null mice, the single mutants were bred and offspring with mutations in both their MMP-9 and MMP-12 genes were identified by Southern blot. The probes for genotyping the animals were obtained from Dr. Werb (Vu et al., 1998) and Dr. Shapiro (Shipley et al., 1996). There was no obvious behavioral phenotype in the single- or double-null mice. Wild-type mice in all cases were 129/SvEv mice bred in-house.

Immunohistochemistry. For ease of sample preparation for immunohistochemistry, we chose to focus on using brains rather than the optic nerve. The corpus callosum in the brain is a well studied region for OL ontogeny (Skoff et al., 1976; Cammer and Zhang, 1992; Gordon et al., 1992), as is the optic nerve. Brains from P7, P10, and P14 mice were carefully removed and immediately fixed in $4 \%$ paraformaldehyde overnight and sucrose protected. They were embedded and sections containing the corpus callosum were cut on a cryostat. Sections from each animal were double-labeled with myelin basic protein (MBP) (mouse monoclonal; 1:150; Sternberger Monoclonals, Lutherville, MD) and neurofilament H (heavy chain; rabbit polyclonal; 1:400; Serotec, Oxford, UK) antibodies. Adjacent sections were used to identify immature and mature OLs, using double labeling with antibodies to platelet-derived growth factor receptor $\alpha$ (PDGF $\alpha \mathrm{R})$ (rabbit polyclonal; 1:100; a gift from Dr. Bill Stallcup, Burnham Institute, San Diego, CA) and CC1 (mouse monoclonal; 1:25; Chemicon, Temecula, CA), respectively. All sections were treated with Triton $\mathrm{X}-100$ for 30 min before blocking with goat serum and then incubated overnight at $4^{\circ} \mathrm{C}$ with the respective antibodies. After incubation with the primary antibody, sections were incubated with secondary antibodies, which were anti-mouse IgG conjugated to Alexa 546 or anti-rabbit IgG conjugated to Alexa 488 (1:500; Invitrogen, Eugene, OR), for $1 \mathrm{~h}$ at room temperature.

Western blot analysis. Brains from P10 mice were used for analysis of myelin products in the developing mouse brain. Total protein was ex-
A.
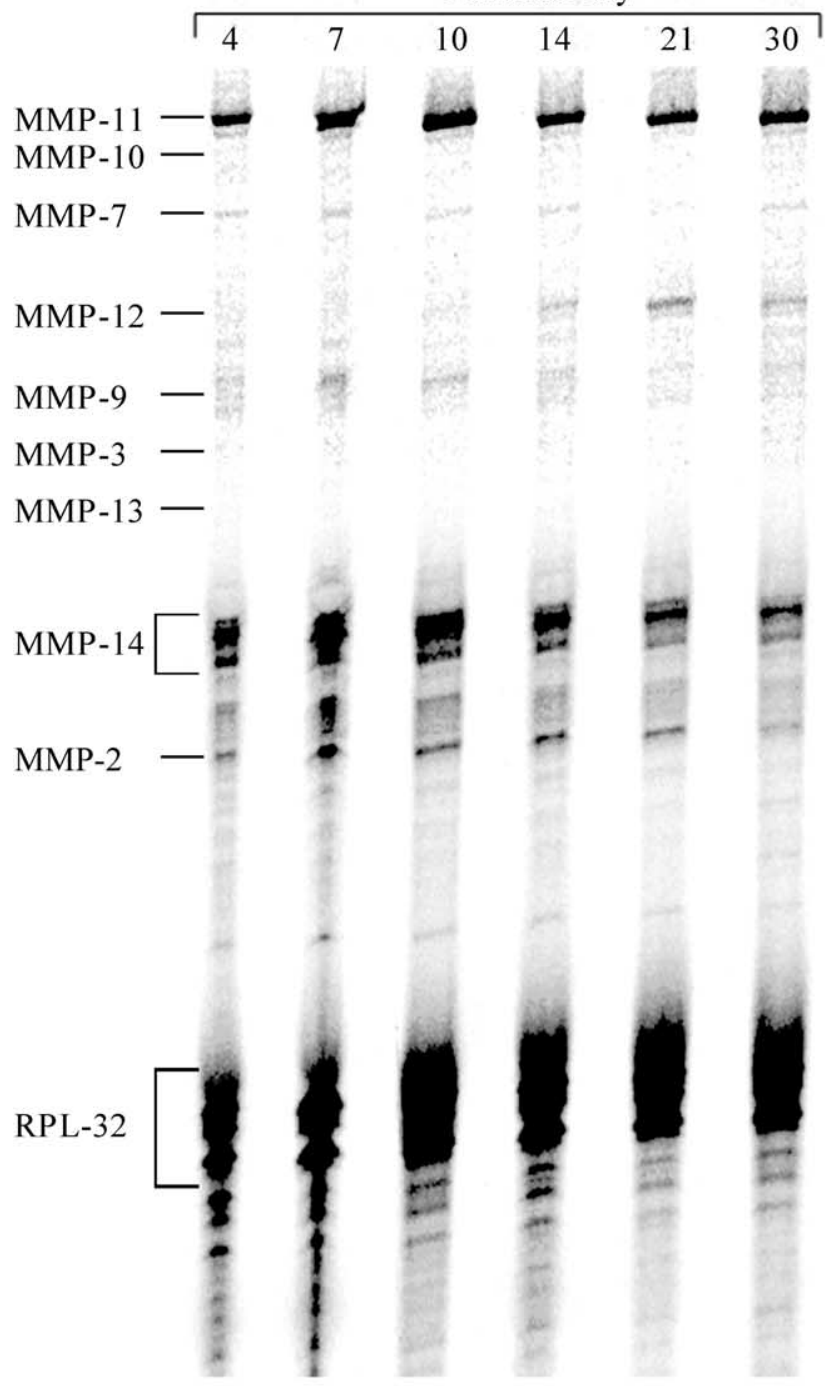

B.

Postnatal day

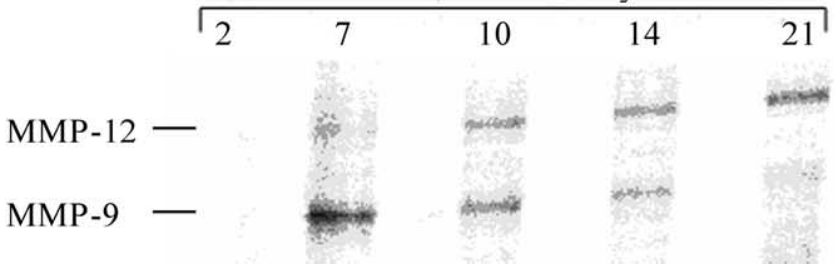

Figure 1. MMP expression profile in mouse optic nerve during postnatal development. RPA analysis revealed that six of the nine MMP members studied were present in the optic nerve at various points from $\mathrm{P} 4$ to $\mathrm{P} 30(\boldsymbol{A})$, with MMP-3, -10 , and -13 being below the limit of detection. Each lane contained pooled RNA extracts from age-matched animals, and the trend of $\boldsymbol{A}$ was observed in five experiments. There was consistently an elevation of MMP-9 and MMP-12, and this is displayed in a different experiment and in a magnified format in $\boldsymbol{B}$. MMP-9 transcripts were elevated at P7 and subsequently decreased from P10 to P21. In contrast, MMP-12 transcripts were progressively elevated from P7 to P21.

tracted by homogenizing the tissue in $1 \%$ SDS extraction buffer $(1 \%$ SDS, $10 \mu \mathrm{g} / \mathrm{ml}$ aprotinin, $10 \mu \mathrm{g} / \mathrm{ml}$ leupeptin, $10 \mu \mathrm{g} / \mathrm{ml}$ pepstatin, and 1 $\mu \mathrm{M}$ PMSF). Homogenate was boiled for $5 \mathrm{~min}$ and centrifuged at 12,000 $\mathrm{rpm}$ for $5 \mathrm{~min}$. The supernatant was obtained and $20 \mu \mathrm{g}$ of total protein was subjected to $12 \%$ SDS-electrophoresis. Gels were transferred to polyvinylidene difluoride membrane and probed with MBP (1:750; antibody described above), IGFBP-6 (1:100; polyclonal rabbit; GroPep, Adelaide, Australia), or $\beta$-actin (1:2000; mouse monoclonal; Santa Cruz Biotech- 

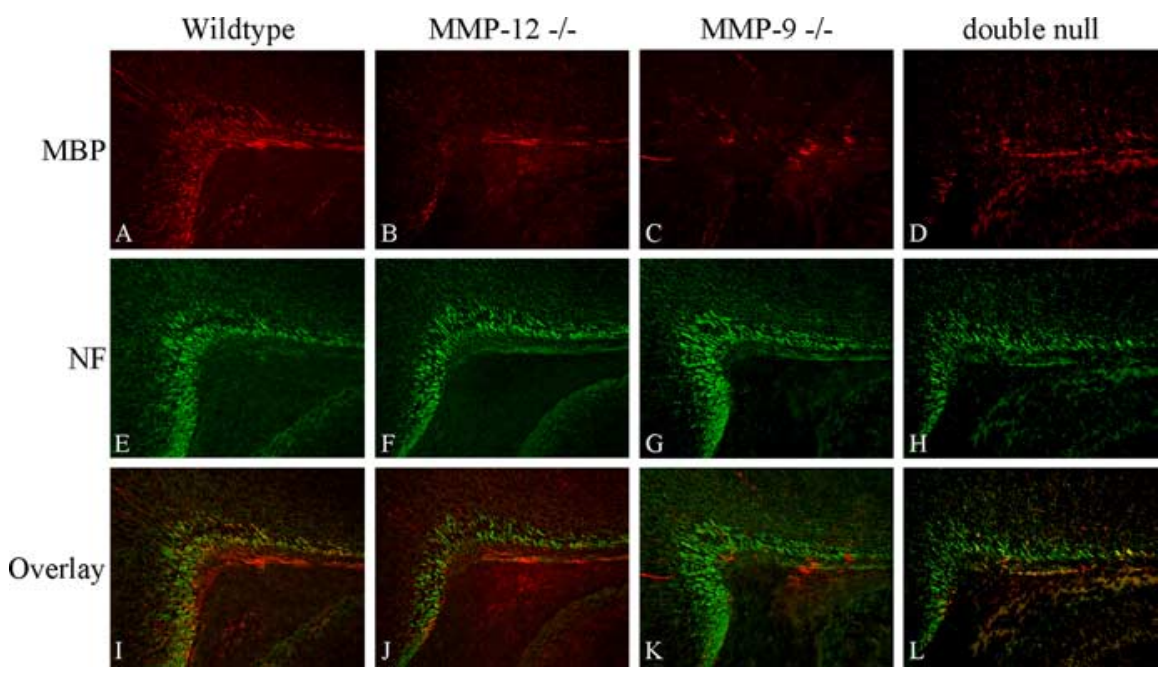

Figure 2. Reduced myelin development in the corpus callosum of MMP-deficient mice at P7. Comparison of MBP (red) at P7 revealed reduced immunoreactivity in similar regions of the corpus callosum in MMP-12(B), MMP-9 (C), and double-mutant mice (D) compared with wild-type mice $(\boldsymbol{A})$. Axonal integrity assessed using a neurofilament (NF) antibody (green) indicated that there was no apparent alteration in the overall development of the axonal tracts between genotypes $(\boldsymbol{E}-\boldsymbol{H})$. Superimposed images of $\boldsymbol{A}-\boldsymbol{D}$ and $\boldsymbol{E}-\boldsymbol{H}$ are visualized in the corresponding bottom panels $(\boldsymbol{I}-\boldsymbol{L})$. All images were captured with the same camera exposure times.

Table 1. Incidence of deficient myelination in P7 mice

\begin{tabular}{lc}
\hline Genotype & Incidence of mice with reduced MBP over number examined \\
\hline Wild type & $1 / 12$ \\
MMP-12 null & $11 / 12$ \\
MMP-9 null & $10 / 10$ \\
MMP-9/12 null & $10 / 10$ \\
\hline
\end{tabular}

The corpus callosum of mice was examined following MBP immunohistochemistry. All mutant genotypes examined with the exception of one MMP-12 null mouse, exhibited a reduction in MBP immunoreactivity.

nology, Santa Cruz, CA) antibodies. Secondary mouse or rabbit antibodies conjugated to horseradish peroxidase together with ECL illuminescence (Amersham Biosciences) were used for detection of the antigens.

Precursor cell purification and IGF-1 treatment. OPCs were purified as described by Larsen and Yong (2004). Briefly, brains were removed from P3 wild-type and MMP-12 null mice and the cells were dissociated by $0.25 \%$ trypsin treatment $(20 \mathrm{~min})$. The cells were then separated from debris using Percoll density centrifugation and incubated with a mouse monoclonal A2B5 antibody (Eisenbarth et al., 1979) for $1 \mathrm{~h}$ at $4^{\circ} \mathrm{C}$, followed by incubation with magnetic bead-coated anti-mouse IgM for 30 $\min$ at $4^{\circ} \mathrm{C}$. Finally, the cells were purified by magnetic sorting according to the manufacturer's instructions (MACS; Miltenyi Biotec, Auburn, CA). The purified OPCs from wild-type or MMP-12 null mice were plated onto 16-well Lab-Tek (Nunc, Naperville, IL) chamber slides coated with poly-L-ornithine at a density of 75,000 cells/well. After cell plating, the $\mathrm{A} 2 \mathrm{~B} 5$ precursors were allowed to mature for $48 \mathrm{~h}$ at $37^{\circ} \mathrm{C}$ in a $5 \% \mathrm{CO}_{2}$ environment. Feeding medium consisted of an OPC differentiation medium (DMEM/F12) containing $100 \mu \mathrm{g} / \mathrm{ml}$ transferrin, $60 \mathrm{ng} / \mathrm{ml}$ progesterone, $30 \mathrm{~nm}$ sodium selenite, $5 \mathrm{mg} / \mathrm{ml}$ dextrose, $30 \mathrm{ng} / \mathrm{ml} \mathrm{T} 3$ (triiodothyronine), $10 \mathrm{~nm}$ D-biotin, $10 \mathrm{ng} / \mathrm{ml}$ PDGF, $1 \mathrm{~mm}$ sodium pyruvate, $2 \mathrm{~mm}$ L-glutamine, and $1 \%$ fetal calf serum (FCS). The number of mature galactocerebroside-positive OLs present after $48 \mathrm{~h}$ in each condition was obtained by counting the total number of labeled $(\mathrm{O} 1+)$ (Sommer and Schachner, 1981) cells within each well.

In some cultures, the MMP-12 null OPCs were treated with 25 or 100 $\mathrm{ng} / \mathrm{ml}$ recombinant human IGF-1 (R\&D Systems, Minneapolis, MN) to address whether this could promote their maturation.

IGFBP-6 cleavage. IGFBP-6 cleavage experiments were performed by incubating recombinant mouse IGFBP-6 ( $25 \mu \mathrm{g} / \mathrm{ml}$; R\&D Systems) with active MMP-9 (2.5 $\mu \mathrm{g} / \mathrm{ml}$; Calbiochem, La Jolla, CA) or MMP-12 (2 $\mu \mathrm{g} / \mathrm{ml}$; R\&D Systems) for $6 \mathrm{~h}$ at $37^{\circ} \mathrm{C}$. BB-94 (batimastat; $1 \mu \mathrm{M}$; British Biotech, Oxford, UK) was used to inhibit metalloproteinase activity in
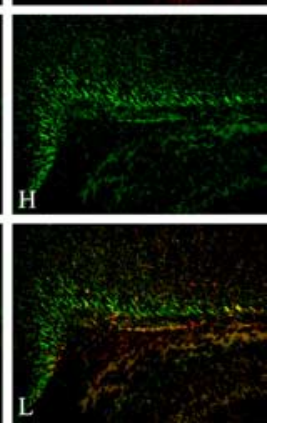

some experiments. Western blot for IGFBP-6 (goat anti-mouse IGFBP-6; R\&D Systems) was then performed.

Statistical analysis. Statistical analyses were performed using one-way ANOVA. Dunnett multiple comparisons were used for post hoc analysis. In all figures, data are presented as mean \pm SEM.

\section{Results \\ MMP expression during developmental myelination}

The expression profile of several MMP genes during developmental myelination was determined using a multiprobe RPA that allows for the simultaneous detection of nine MMP members. Mouse optic nerves were dissected at various developmental postnatal times from P2 to P30. Myelination in the mouse optic nerve usually commences $\sim \mathrm{P} 5-\mathrm{P} 6$, and its progression then is most intense from the second week to the fourth week postnatally (Sefton et al., 1985; Dangata and Kaufman, 1997). Six of the nine MMP members were present in the optic nerve (MMP-2, -7, -9, $-11,-12,-14)$, whereas MMP-3, -10 , and -13 were below the limit of detection (Fig. 1A). Of the six MMP members present, only MMP-9 and MMP-12 changed their expression profile noticeably over the time course studied. MMP- 9 was elevated at $\sim \mathrm{P} 7$, with subsequently lower levels detected at P10 and P14 (Fig. 1 B). Conversely, MMP-12 levels increased progressively from P7 to P21. Thus, MMP-9 was present during the initiation of myelin formation, whereas MMP-12, although also present at the onset of myelinogenesis, continued to increase its expression at later stages when myelination was proceeding a rapid rate.

\section{Altered developmental expression of myelin basic protein in MMP-null mice}

To determine whether MMP-9 and -12 have functional roles in developmental myelination, mice deficient for MMP-9 and MMP-12 were studied with respect to myelin development. Furthermore, MMP-9/12 double-null mice were also examined for their capacity to initiate myelination. We focused on the corpus callosum because the larger area of this structure compared with the early postnatal optic nerve allowed for a more thorough examination of the extent of myelin formation.

Similar regions of the corpus callosum were analyzed for the expression of MBP, a protein present in myelin and a marker of myelination. In P7 mice, we found that MMP-12 null animals had less MBP-positive profiles compared with wild-type mice (Fig. 2A,B). Similarly, MMP-9 and double null mice at P7 had reduced MBP staining (Fig. $2 C, \mathrm{D}$ ) in the corpus callosum compared with wild-type animals. The incidence of mice with reduced MBP immunoreactivity is tabulated in Table 1, and the data were accumulated across several litters with consistent observations.

Given the mutual sustenance of axons and myelin as noted previously, and to rule out the possibility that the observed reduction of MBP immunoreactivity was attributable to an overall delay in the development of the corpus callosum, adjacent sections were labeled for axons. Similar neurofilament $\mathrm{H}$ immunoreactivity was observed across the different genotypes at P7 (Fig. 
$2 E-H)$, suggesting that axonal development in the corpus callosum was not affected by deletion of either MMP-9 or MMP-12.

\section{The decreased myelination in MMP-null} mice is transient

We investigated later stages of myelination to address whether the difference in MBP immunoreactivity observed in the MMP mutants at P7 was transient or longlasting. In previous investigations of adult mice (2-3 months of age) subjected to lysolecithin-induced demyelination, we had noted that the amount of myelin was not different between wild-type and MMP-9 null mice before injury (Larsen et al., 2003). Thus, we examined the corpus callosum of P10 and P14 mice. We found that there was still deficient MBP immunoreactivity in P10 MMP-9, -12, or double-null mice compared with agematched wild type (data not shown), and this deficiency was similar to the extent observed at P7. However, at P14, there were no longer any apparent differences in MBP immunoreactivity between the genotypes compared with wild type (Fig. $3 A-D$ ). Thus, the deficiency of myelin formation in MMP-9 and -12 null mice was transient, being apparent at P7 and P10, but no longer visible at P14.

Western blot analysis was performed to confirm and quantitate the observations by immunohistochemistry of delayed myelin formation in MMP-deficient animals. Total brain homogenates from P10 mice were probed for MBP, and this was normalized to $\beta$-actin signals. In wild-type mice, the antibody to MBP detected four prominent bands, in accordance with reports that there are at least four different MBP isoforms ( 21.5, 18.5, 17, and $14 \mathrm{kDa}$ ) (Campagnoni et al., 1987; Ye et al., 2002). Compared with wild-type specimens, a reduction in the 21.5 and 18.5 $\mathrm{kDa}$ forms was visually apparent in samples from the MMP-9 and -12 single- and double-null genotypes (Fig. 4A). Image analyses of scanned gels confirmed that the $21 \mathrm{kDa}$ form of MBP was significantly reduced in the MMP-null samples relative to wild type (Fig. $4 B$ ). The $14 \mathrm{kDa}$ MBP species did not appear altered between the genotypes, whereas the $18.5 \mathrm{kDa}$ isoform, although visually reduced in MMP-null mice relative to wild-type animals, could not be quantitatively compared because of its absence in the MMP-null animals. These results support the immunohistochemistry results of a decrease of MBP and myelination in MMP-9 and -12 null mice.

It has been noted for some time that a fifth MBP isoform may exist, at least as evaluated by cDNA clones, and that its predicted mass is $\sim 17 \mathrm{kDa}$ (Newman et al., 1987). More recently, Kruger et al. (1999) reported that a $16 \mathrm{kDa}$ form, aside from the 21.5, 18.5, 17 , and $14 \mathrm{kDa}$ forms, could be detected by Western blot analyses in the brains of P11 rat brains, but not when these animals were at P70. In vitro, the $16 \mathrm{kDa}$ isoform was found by Western blots in cultures growing for 2 weeks, but not 3 weeks (Kruger et al., 1999), suggesting that this was an immature form of MBP that declined with maturity. Interestingly, in the P10 wild-type brains in this study (Fig. 4A), a $16 \mathrm{kDa}$ form was barely discernible in the wild-type samples, and the level of this was increased in brains from MMP-null mice.

Overall, and consistent with immunohistochemistry, the
A.

MBP Wildtype MMP-12 -/- MMP-9-/- double null kDa

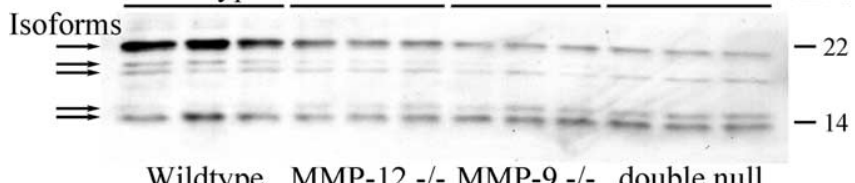

Actin Wildtype MMP-12 -/- MMP-9 -/- double null

B.

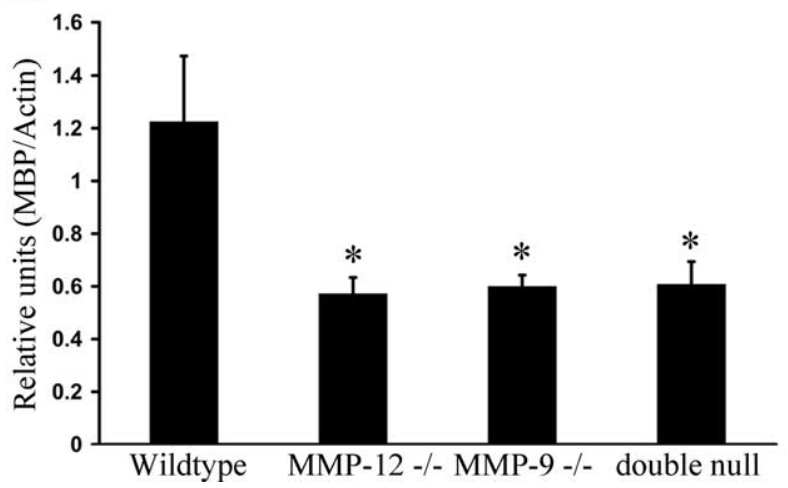

Figure 4. Delay in overall MBP protein production in total brain is verified by Western blot. Confirmation of the reduced MBP immunoreactivity in tissue sections was obtained using Western blot analysis of whole-brain lysates of $\mathrm{P} 10$ animals. In $A$, the five $\mathrm{MBP}$ isoforms, indicated by arrows from top to bottom, are of $21.5,18.5,17,16$, and $14 \mathrm{kDa}$. Three mice per genotype were analyzed here. In $\boldsymbol{B}$, the density of the $21.5 \mathrm{kDa} \mathrm{MBP}$ isoform, normalized to $\beta$-actin, is displayed. ${ }^{*} p<0.05$ compared with wild-type mice. Error bars indicate SEM.

Western blot results support the finding of a transient delay in developmental myelination in MMP-9 and -12 null mice. In all cases of MBP immunohistochemistry or Westerns analyzed (Figs. 2 and 4), we did not find that the deficit in the double-null mice was exaggerated when compared with the single MMP-9 or -12 animals.

MMP-null mice have reduced number of mature OLs

Because myelin is formed from mature OLs, we investigated whether the deficiency of myelination in MMP-null mice was a result of the lack of OLs or OPCs. Sections of the corpus callosum 
A. OPCs (PDGFR $\alpha)$

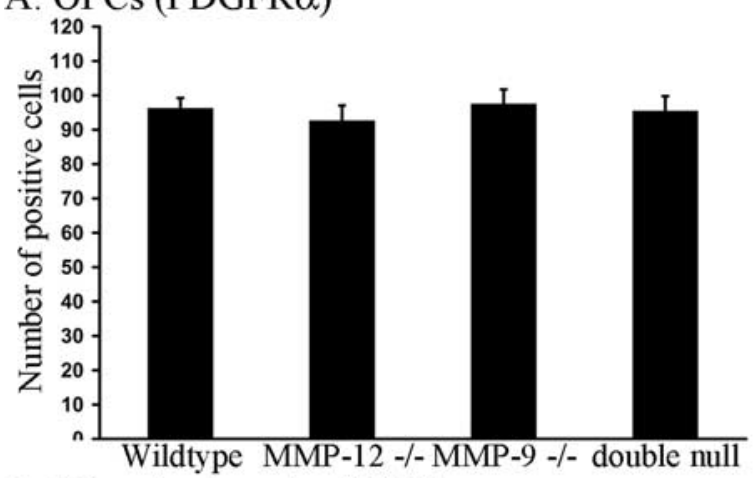

B. Oligodendrocytes $(\mathrm{CC} 1)$

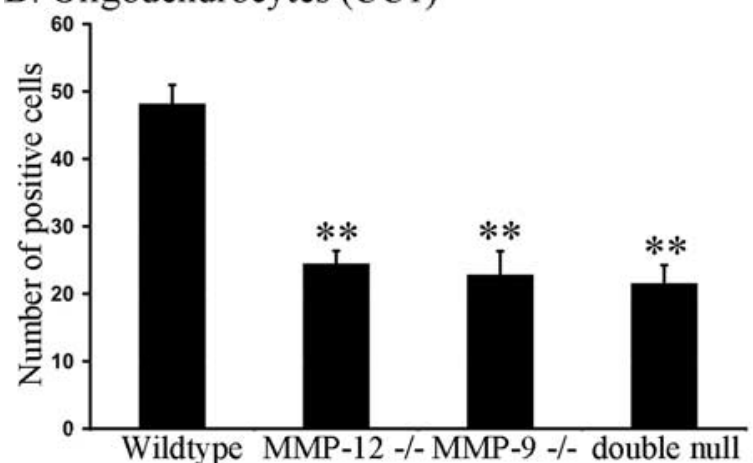

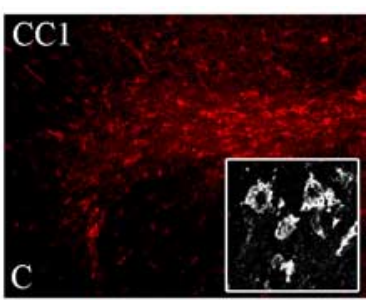
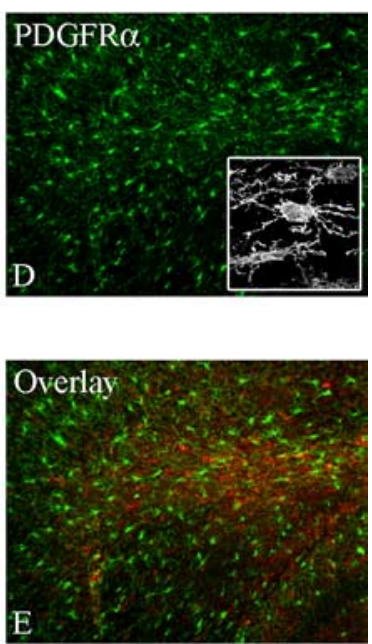

Figure 5. Deficient number of $0 \mathrm{Ls}$ in the corpus callosum of P10 MMP-null mice. $\boldsymbol{A}$, The number of PDGFR $\alpha$-positive $0 \mathrm{~L}$ precursor cells (OPCs) was similar between wild-type and MMP-null mice. $\boldsymbol{B}$, Conversely, the number of CC1-positive mature $0 \mathrm{Ls}$ in MMP-null mice was reduced to $\sim 50 \%$ of wild-type numbers. Each bar represents the mean \pm SEM number of cells from three to five mice, where four sections were evaluated per mice. ${ }^{* *} p<0.01$ compared with wild type. $\boldsymbol{C}-\boldsymbol{E}$, Representative pictures of CC1-positive cells (red), PDGFR $\alpha$ immunoreactivity (green), and the overlay, respectively. The insets of $\boldsymbol{C}$ and $\boldsymbol{D}$ are highmagnification micrographs to depict the cells of interest.

at P10 were compared between wild-type and null mice after immunolabeling for PDGF $\alpha$ R-positive cells, which labels OPCs (Pringle and Richardson, 1993; Hall et al., 1996), and for CC1 (Fuss et al., 2000; Messersmith et al., 2000), a marker of mature OLs. In each animal, cell counts were made in four sections spaced $100 \mu \mathrm{m}$ apart. There were no differences in the number of PDGF $\alpha$ R-positive cells between the genotypes (Fig. 5A). However, a significant decrease in the number of mature OLs (CC1positive) was observed in all mutant mice when compared with wild type (Fig. 5B). Representative images are shown in Figure $5 C-E$. Thus, our results indicate that the delay in myelination in MMP-deficient mice is attributable to a decreased number of mature OLs. Because the number of OPCs is not different between the genotypes, these data suggest that MMPs are involved in regulating the maturation of OLs or their survival.

\section{IGF-1 normalizes the decreased number of OLs in} MMP-null cultures

A key growth factor that regulates the maturation and survival of OLs is IGF-1 (for review, see D'Ercole et al., 2002). We addressed whether the lack of mature OLs in MMP-9 and MMP-12 null mice could be reproduced in vitro and, if so, whether this was attributable to alterations in IGF bioavailability. We focused on the MMP-12 null mice, because we have previously found that there was a reduced number of mature OLs in this genotype that develop from OPCs in culture (Larsen and Yong, 2004). In the current series, OPCs were allowed to mature for $48 \mathrm{~h}$ in vitro with or without IGF-1 treatment. Counting of the number of O1positive mature OLs confirmed our previous finding that there was deficient maturation of cells in the MMP-12 null group compared with wildtype cultures (Fig. 6). Significantly, this deficiency of mature OLs in MMP-12 null cultures was overcome and normalized to wild-type levels by the addition of IGF-1 (Fig. 6). Both concentrations of IGF-1 tested were comparable in efficacy. These results suggest that the reduced bioavailability of IGF-1 contributes to the lack of maturation of OLs in the MMP genotypes.

IGFBP-6 is a substrate for MMP and its level is elevated in MMP-null mice We addressed whether IGFBP-6 was involved in regulating the bioavailability of IGF-1 and thus the reduced maturation of OLs in the context of MMP deficiency. First, we examined whether recombinant IGFBP- 6 could be processed by MMP-9 and -12 . After incubation of IGFBP-6 with active MMP-9 (Fig. 7A) or MMP-12 (Fig. $7 B$ ), the parent IGFBP-6 compound was reduced in level while lower molecular weight fragments became visible. The results indicate that IGFBP-6 was a substrate for MMP-9 and -12 processing, and this was confirmed by the retention of the parent compound when IGFBP-6 was incubated with MMP-9 in the presence of a metalloproteinase inhibitor, BB-94.

To examine the interaction of MMPs with IGFBP-6 in vivo, we measured the level of IGFBP- 6 in whole brain of P10 mice by Western blot analysis. Figure $7 C$ shows that IGFBP-6 is present during myelinogenesis. That IGFBP-6 is a substrate for MMP in vivo is denoted by the increase in IGFBP-6 content in MMP-9- and double-null mice compared with wild type. The level of IGFBP-6 is higher in the MMP-12-null mice compared with wild type, but this did not attain statistical significance.

In aggregate, these findings support the conclusion that IGFBP-6 is a substrate for MMP-9 and -12 and that the lack of these MMPs results in the higher level of IGFBP- 6 in null mice versus wild type, thereby reducing myelination by limiting the availability of IGF-1.

\section{Discussion}

The upregulation of MMPs in the CNS has traditionally been thought to impart detrimental consequences, and this has been supported by data that the sudden and massive increase of several MMP members after CNS injury promotes neuroinflammation, produces demyelination, and inflicts neurotoxicity (Yong et al., 2001; Lee et al., 2004). However, the discrete expression of MMPs in a temporal and spatial manner may have beneficial effects on CNS development or recovery (Yong, 2005), given the recognition that MMPs regulate the apoptosis and survival of several cell types and have roles in cell signaling (Egeblad and Werb, 2002; Parks et al., 2004). In line with the favorable roles of MMPs is our observation that MMP-9 and -12 regulate the maturation of OLs and their process-extending capacity in vitro (Uhm et al., 1998; Oh et al., 1999; Larsen and Yong, 2004). We also noted that, during remyelination in adult mice in vivo, the focal expression of MMP-9 at injury sites served to clear an inhibitory proteoglycan 

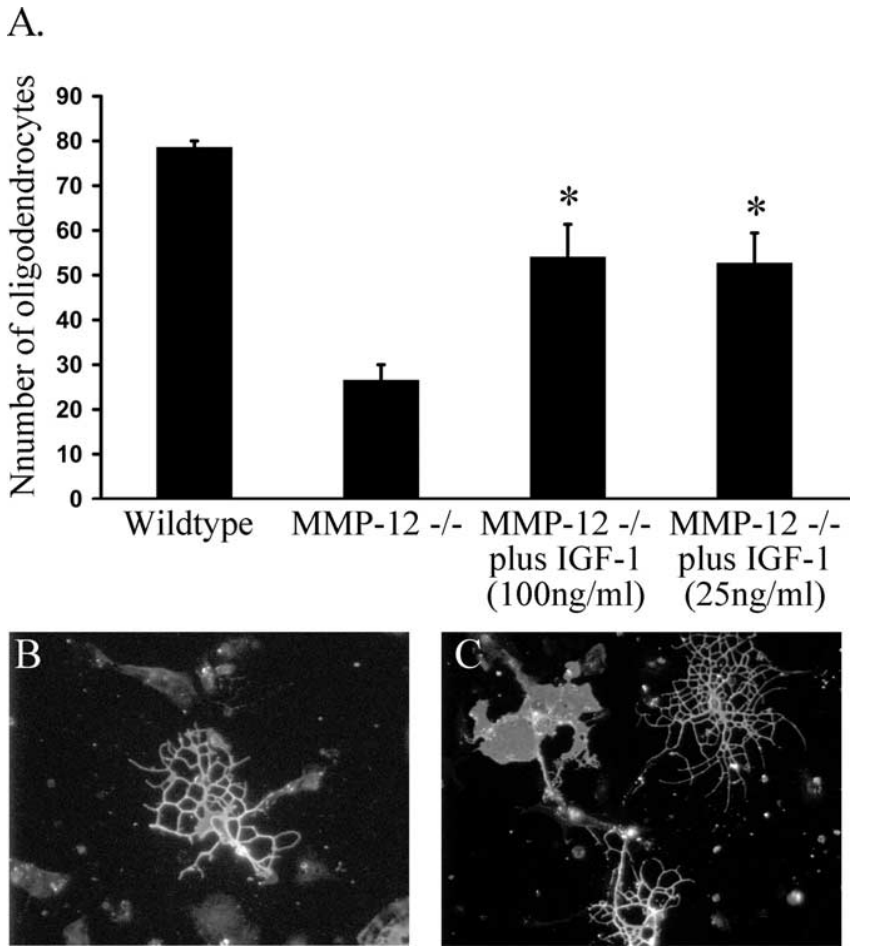

Figure 6. IGF-1 normalizes the decreased number of $0 \mathrm{Ls}$ in MMP-null cultures. $\boldsymbol{A}$, The number of mature $0 \mathrm{Ls}$ developing from progenitors was determined ( $y$-axis) per culture. There was a deficiency of mature 0 Ls in MMP-12-null cultures compared with wild type, but the addition of IGF-1 for $48 \mathrm{~h}$ to MMP-12-null cells increased the number of mature 0Ls to approximate wild-type numbers. Both concentrations of IGF-1 gave comparable results. Values are mean \pm SEM of the number of $0 \mathrm{~L}$ s in three to four cultures. ${ }^{*} p<0.05$ compared with MMP-12-null cells. $B$ represents a control MMP-12-null culture, whereas $C$ has been exposed to IGF-1. Mature $0 \mathrm{Ls}$ of many morphologies are encountered.

barrier and that such clearance of a nonpermissive substrate then allowed OLs to mature and reform myelin (Larsen et al., 2003). Despite these advances, the possibility that MMPs have functions in developmental myelination, when the extent of myelinogenesis is most robust compared with myelin turnover or remyelination in adulthood, is unknown. In this study, we have investigated whether and how MMPs may have roles in developmental myelin formation in the mouse CNS.

Using an RPA assay that allowed the simultaneous detection of nine MMP members, we show that MMP-9 and MMP-12 transcripts are selectively upregulated in the optic nerve at periods correlating with myelination; a correlation between the upregulation of MMP-12 transcript and myelination in the rhombencephalon and spinal cord of mice was recently reported (Ulrich et al., 2005). We found that the elevation of MMP-9 and -12 has functional roles, because there is deficient myelination in MMP-9 and -12 null mice from P7 to P14. The deficient myelination was not the result of a delay in the overall development of mice, because axonal profiles were comparable across the genotypes. Investigations of OL cell numbers in MMP-9 and -12deficient mice revealed a $50 \%$ reduction in the number of mature OLs compared with wild-type controls (Fig. 5). Because there was no difference in PDGF $\alpha$ R-positive OPCs across genotypes, this suggests that precursor cells were not maturing into OLs in appropriate numbers for developmental myelination to proceed at a normal rate.

Several molecules are involved in the differentiation of OL and myelination (Barres et al., 1993). For example, changes in
A.

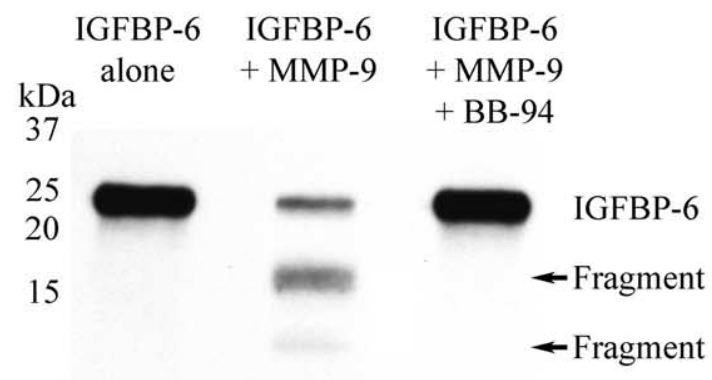

B.
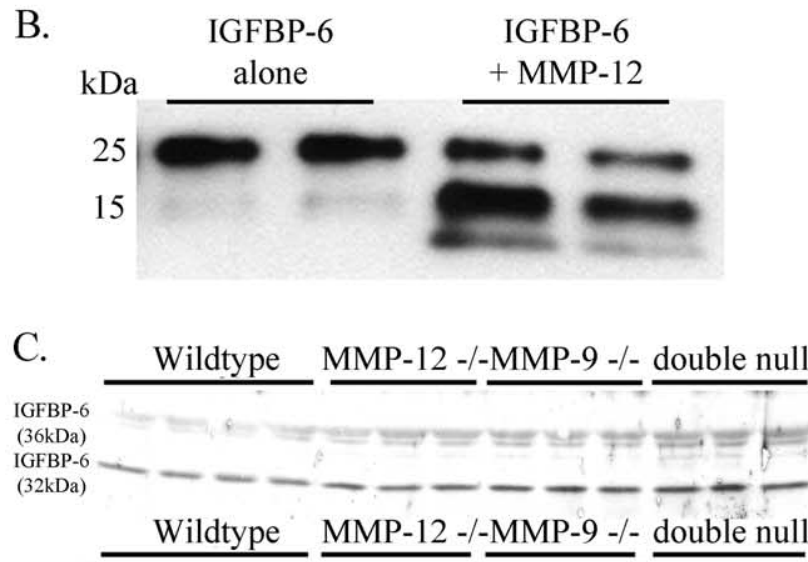

Actin

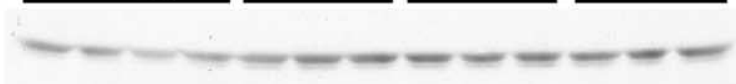

$\mathrm{D}$

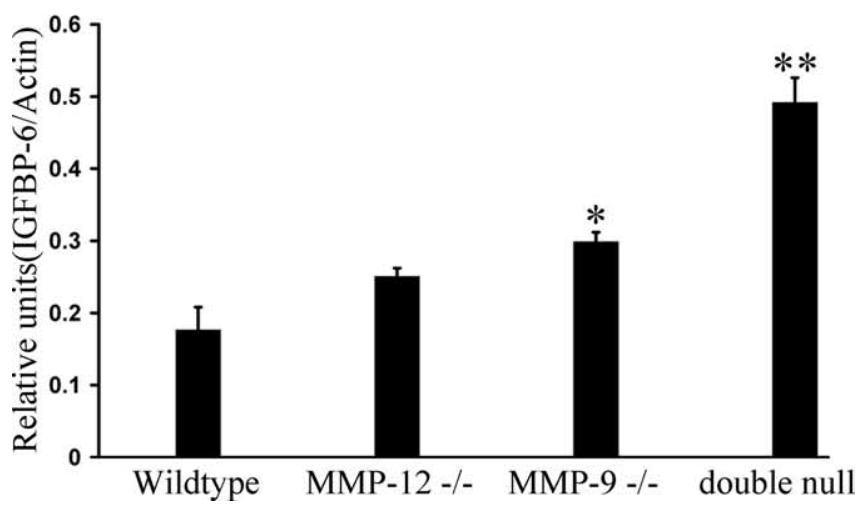

Figure 7. Elevation of IGFBP-6 in MMP-null mice at postnatal day 10 . $\boldsymbol{A}$ demonstrates that MMP-9 can cleave the parent IGFBP-6 protein (lane 1) into smaller fragments (lane 2) and that this proteolytic event can be inhibited by BB-94 (lane 3). In $\boldsymbol{B}$, the Western blot for IGFBP-6 shows the parent compound (first 2 lanes) and the generation of new fragments when the parent compound is incubated with MMP-12 (next 2 lanes). C displays Western blot analysis of total brain extract from three animals each of wild-type and MMP-null mice; actin was used as a loading control. In $\boldsymbol{D}$, quantitation of both the 32 and $36 \mathrm{kD}$ a species of IGFBP-6 shows a slight increase in the single-null genotype compared with wild type, and this was exacerbated in the double-null mice. Each bar is the mean \pm SEM from three or four mice. ${ }^{*} p<0.05 ;{ }^{* *} p<0.01$ compared with wild type.

polysialylated-neural cell-adhesion molecules (PSA-NCAM) are linked to the initiation of myelination (Charles et al., 2000). A chemokine, CXCL1 (CXC chemokine ligand 1) [GRO- $\alpha$ (growth-related oncogene $\alpha$ )], is important for OL migration (Tsai et al., 2002), and the Notch/Jagged pathway has been implicated to play a role in remyelination in lesions of multiple sclerosis patients (John et al., 2002). Another important molecule for myelin formation is IGF-1, which regulates not only the maturation of OLs but also their survival (Barres et al., 1993; Ye and 
D'Ercole, 1999; D'Ercole et al., 2002). In line with this is the enhancement of developmental myelination in IGF-1 transgenic mice (Carson et al., 1993) and its reduction in IGF-1-null mice (Ye et al., 2002). In animals with disrupted IGF-1 receptor signaling, remyelination is impaired after cuprizone-induced demyelination in adult mice (Mason et al., 2003).

In this study, we focused on the possibility that the deficiency of myelination in MMP-null mice is the result of altered IGF-1 signaling because the bioavailability of IGFs is regulated by IGFBPs and MMPs can cleave IGFBPs without degrading the bound IGF (Bunn and Fowlkes, 2003; Sadowski et al., 2003; Fowlkes et al., 2004; Miyamoto et al., 2004). In this manner, MMPs would play a role in myelination through controlling the bioavailability of IGF-1. We addressed IGFBP-6 specifically because IGFBP-6 is synthesized in the CNS (Mewar and McMorris, 1997) and IGFBP-6 transgenic mice show a number of CNS defects such as reduced cerebellum and reduced astrocyte numbers (Bienvenu et al., 2004). Moreover, the decreasing levels in cultures of IGFBP-6 coincide with increasing maturation of OLs and IGFBP- 6 added exogenously led to decreased survival of OPCs and the expression of myelin proteins (Kuhl et al., 2003). Thus, we found that IGFBP-6 levels was relatively high in the brains of MMP-null mice compared with wild type, suggesting that IGFBP-6 was a substrate for MMP-9 and -12 in vivo and that its continued high expression sequestered IGF-1 and reduced its availability for OLs to mature and myelinate. In support, progenitor cells from MMP-12 null mice were less able to mature to OLs in culture, and this was overcome by the exogenous addition of IGF-1.

Thus, our results favor a model in which MMP-9 and -12 expression is required for processing of IGFBP- 6 to free IGF- 1 for OLs to mature and form myelin. Nonetheless, we cannot rule out the possibility that other mechanisms of MMP-9 and -12 are involved, such as their potential effect on PSA-NCAM, Notch signaling, or the removal of inhibitory proteoglycans. These are topics for future studies.

Are MMP-9 and -12 acting through precisely the same mechanisms to regulate myelinogenesis? We cannot be certain, but because MMP-9 and -12 double-null mice do not show an exaggerated outcome in MBP expression and OL numbers compared with the single deficiency, it is possible that both MMPs work through similar mechanisms. It is possible that MMP-9 and -12 both contribute early on in myelinogenesis, consistent with their early expression at P7, but that MMP-12 becomes more dominant later on as its content continues to rise with maturity. We note that IGFBP-6 content is enhanced in double-null mice compared with the single deficiency (Fig. 7), and it is likely that this reflects a greater efficiency in removing IGFBP when both proteases are present. Until the entire spectrum of activity of MMPs in developmental myelinogenesis is elucidated, the question of whether MMP-9 and -12 works through similar mechanisms cannot be conclusively addressed.

We note that the deficient myelination in MMP-9 and -12 null mice was a temporary phenomenon from P7 to P14, because a comparable extent of myelin markers is evident at P14 between wild-type and MMP-null mice. This could reflect redundancy of proteases, because other MMPs are also found in the CNS at P7-P14 (Fig. 1), or it could reflect relevant growth factors such as IGF-1 being made available through alternate mechanisms. In reviewing the literature, we note that the phenotypes described in MMP-9 null mice, such as reduced growth of long bones ( $\mathrm{Vu}$ et al., 1998) or altered axonal outgrowth in the cerebellum (Vaillant et al., 2003), have all tended to be transient. Nonetheless, our results help pinpoint mechanisms by which myelinogenesis oc- curs, because we now add the expression of MMPs to the list of factors that regulate this process.

In conclusion, we have observed that an increase in MMP-9 and -12 in early postnatal development helps to regulate myelinogenesis. We propose a mechanism whereby the expression of MMP-9 and - 12 removes IGFBP-6, thereby freeing IGF-1 to drive OL maturation and myelination. Our study advances the knowledge of developmental myelination, and it sheds light on future strategies to repair myelin in the adult CNS after a demyelinating insult.

\section{References}

Barres BA, Schmid R, Sendnter M, Raff MC (1993) Multiple extracellular signals are required for long-term oligodendrocyte survival. Development 118:283-295.

Bienvenu G, Seurin D, Grellier P, Froment P, Baudrimont M, Monget P, Le Bouc Y, Babajko S (2004) Insulin-like growth factor binding protein-6 transgenic mice: postnatal growth, brain development, and reproduction abnormalities. Endocrinology 145:2412-2420.

Bunn RC, Fowlkes JL (2003) Insulin-like growth factor binding protein proteolysis. Trends Endocrinol Metab 14:176-181.

Cammer W, Zhang H (1992) Localization of Pi class glutathione-Stransferase in the forebrains of neonatal and young rats: evidence for separation of astrocytic and oligodendrocytic lineages. J Comp Neurol 321:40-45.

Campagnoni AT, Sorg B, Roth HJ, Kronquist K, Newman SL, Kitamura K, Campagnoni C, Crandall B (1987) Expression of myelin protein genes in the developing brain. J Physiol (Paris) 82:229-238.

Carson MJ, Behringer RR, Brinster RL, McMorris FA (1993) Insulin-like growth factor I increases brain growth and central nervous system myelination in transgenic mice. Neuron 10:729-740.

Charles P, Hernandez MP, Stankoff B, Aigrot MS, Colin C, Rougon G, Zalc B, Lubetzki C (2000) Negative regulation of central nervous system myelination by polysialylated-neural cell adhesion molecule. Proc Natl Acad Sci USA 97:7585-7590.

Dangata YY, Kaufman MH (1997) Myelinogenesis in the optic nerve of $(\mathrm{C} 57 \mathrm{BL} \times \mathrm{CBA}) \mathrm{F}_{1}$ hybrid mice: a morphometric analysis. Eur J Morphol 35:3-17.

D’Ercole AJ, Ye P, O’Kusky JR (2002) Mutant mouse models of insulin-like growth factor actions in the central nervous system. Neuropeptides 36:209-220.

Egeblad M, Werb Z (2002) New functions for the matrix metalloproteinases in cancer progression. Nat Rev Cancer 2:161-174.

Eisenbarth GS, Walsh FS, Nirenberg M (1979) Monoclonal antibody to a plasma membrane antigen of neurons. Proc Natl Acad Sci USA 76:4913-4917.

Fowlkes JL, Serra DM, Bunn RC, Thrailkill KM, Enghild JJ, Nagase H (2004) Regulation of insulin-like growth factor (IGF)-I action by matrix metalloproteinase-3 involves selective disruption of IGF-I/IGF-binding protein-3 complexes. Endocrinology 145:620-626.

Fuss B, Mallon B, Phan T, Ohlemeyer C, Kirchhoff F, Nishiyama A, Macklin WB (2000) Purification and analysis of in vivo-differentiated oligodendrocytes expressing the green fluorescent protein. Dev Biol 218:259-274.

Gordon MN, Kumar S, Espinosa de los Monteros A, de Vellis J (1992) Ontogeny of glycerol phosphate dehydrogenase-positive oligodendrocytes in rat brain. Impaired differentiation of oligodendrocytes in the myelin deficient mutant rat. Int J Dev Neurosci 10:243-253.

Hall A, Giese NA, Richardson WD (1996) Spinal cord oligodendrocytes develop from ventrally derived progenitor cells that express PDGF alphareceptors. Development 122:4085-4094.

John GR, Shankar SL, Shafit-Zagardo B, Massimi A, Lee SC, Raine CS, Brosnan CF (2002) Multiple sclerosis: re-expression of a developmental pathway that restricts oligodendrocyte maturation. Nat Med 8:1115-1121.

Kruger GM, Diemel LT, Copelman CA, Cuzner ML (1999) Myelin basic protein isoforms in myelinating and remyelinating rat brain aggregate cultures. J Neurosci Res 56:241-247.

Kuhl NM, Hoekstra D, De Vries H, De Keyser J (2003) Insulin-like growth factor-binding protein 6 inhibits survival and differentiation of rat oligodendrocyte precursor cells. Glia 44:91-101.

Lappe-Siefke C, Goebbels S, Gravel M, Nicksch E, Lee J, Braun PE, Griffiths 
IR, Nave KA (2003) Disruption of Cnp1 uncouples oligodendroglial functions in axonal support and myelination. Nat Genet 33:366-374.

Larsen PH, Yong VW (2004) The expression of matrix metalloproteinase-12 by oligodendrocytes regulates their maturation and morphological differentiation. J Neurosci 24:7597-7603.

Larsen PH, Wells JE, Stallcup WB, Opdenakker G, Yong VW (2003) Matrix metalloproteinase- 9 facilitates remyelination in part by processing the inhibitory NG2 proteoglycan. J Neurosci 23:11127-11135.

Lee SR, Wang X, Tsuji K, Lo EH (2004) Extracellular proteolytic pathophysiology in the neurovascular unit after stroke. Neurol Res 26:854-861.

Mason JL, Xuan S, Dragatsis I, Efstratiadis A, Goldman JE (2003) Insulinlike growth factor (IGF) signaling through type 1 IGF receptor plays an important role in remyelination. J Neurosci 23:7710-7718.

Messersmith DJ, Murtie JC, Le TQ, Frost EE, Armstrong RC (2000) Fibroblast growth factor 2 (FGF2) and FGF receptor expression in an experimental demyelinating disease with extensive remyelination. J Neurosci Res 62:241-256.

Mewar R, McMorris FA (1997) Expression of insulin-like growth factorbinding protein messenger RNAs in developing rat oligodendrocytes and astrocytes. J Neurosci Res 50:721-728.

Miyamoto S, Yano K, Sugimoto S, Ishii G, Hasebe T, Endoh Y, Kodama K, Goya M, Chiba T, Ochiai A (2004) Matrix metalloproteinase-7 facilitates insulin-like growth factor bioavailability through its proteinase activity on insulin-like growth factor binding protein 3. Cancer Res 64:665-671.

Newman S, Kitamura K, Campagnoni AT (1987) Identification of a cDNA coding for a fifth form of myelin basic protein in mouse. Proc Natl Acad Sci USA 84:886-890

Oh LY, Larsen PH, Krekoski CA, Edwards DR, Donovan F, Werb Z, Yong VW (1999) Matrix metalloproteinase-9/gelatinase B is required for process outgrowth by oligodendrocytes. J Neurosci 19:8464-8475.

Pagenstecher A, Stalder AK, Kincaid CL, Shapiro SD, Campbell IL (1998) Differential expression of matrix metalloproteinase and tissue inhibitor of matrix metalloproteinase genes in the mouse central nervous system in normal and inflammatory states. Am J Pathol 152:729-741.

Parks WC, Wilson CL, Lopez-Boado YS (2004) Matrix metalloproteinases as modulators of inflammation and innate immunity. Nat Rev Immunol 4:617-629.

Pollak MN, Schernhammer ES, Hankinson SE (2004) Insulin-like growth factors and neoplasia. Nat Rev Cancer 4:505-518.

Pringle NP, Richardson WD (1993) A singularity of PDGF alpha-receptor expression in the dorsoventral axis of the neural tube may define the origin of the oligodendrocyte lineage. Development 117:525-533.

Rosenzweig SA (2004) What's new in the IGF-binding proteins? Growth Horm IGF Res 14:329-336.

Sadowski T, Dietrich S, Koschinsky F, Sedlacek R (2003) Matrix metalloproteinase 19 regulates insulin-like growth factor-mediated proliferation, migration, and adhesion in human keratinocytes through proteolysis of insulin-like growth factor binding protein-3. Mol Biol Cell 14:4569-4580.

Sefton AJ, Horsburgh GM, Lam K (1985) The development of the optic nerve in rodents. Aust N Z J Ophthalmol 13:135-145.

Shipley JM, Wesselschmidt RL, Kobayashi DK, Ley TJ, Shapiro SD (1996) Metalloelastase is required for macrophage-mediated proteolysis and matrix invasion in mice. Proc Natl Acad Sci USA 93:3942-3946.

Skoff RP, Price DL, Stocks A (1976) Electron microscopic autoradiographic studies of gliogenesis in rat optic nerve. I. Cell proliferation. J Comp Neurol 169:291-312.

Sommer I, Schachner M (1981) Monoclonal antibodies (O1 to O4) to oligodendrocyte cell surfaces: an immunocytological study in the central nervous system. Dev Biol 83:311-327.

Trapp BD, Nishiyama A, Cheng D, Macklin W (1997) Differentiation and death of premyelinating oligodendrocytes in developing rodent brain. J Cell Biol 137:459-468.

Tsai HH, Frost E, To V, Robinson S, Ffrench-Constant C, Geertman R, Ransohoff RM, Miller RH (2002) The chemokine receptor CXCR2 controls positioning of oligodendrocyte precursors in developing spinal cord by arresting their migration. Cell 110:373-383.

Uhm JH, Dooley NP, Oh LY, Yong VW (1998) Oligodendrocytes utilize a matrix metalloproteinase, MMP-9, to extend processes along an astrocyte extracellular matrix. Glia 22:53-63.

Ulrich R, Gerhauser I, Seeliger F, Baumgartner W, Alldinger S (2005) Matrix metalloproteinases and their inhibitors in the developing mouse brain and spinal cord: a reverse transcription quantitative polymerase chain reaction study. Dev Neurosci 27:408-418.

Vaillant C, Meisserel C, Mutin M, Belin MF, Lund LR, Thomasset N (2003) MMP-9 deficiency affects axonal outgrowth, migration, and apoptosis in the developing cerebellum. Mol Cell Neurosci 24:395-408.

Vu TH, Shipley JM, Bergers G, Berger JE, Helms JA, Hanahan D, Shapiro SD, Senior RM, Werb Z (1998) MMP-9/gelatinase B is a key regulator of growth plate angiogenesis and apoptosis of hypertrophic chondrocytes. Cell 93:411-422.

Ye P, D’Ercole AJ (1999) Insulin-like growth factor I protects oligodendrocytes from tumor necrosis factor-alpha-induced injury. Endocrinology 140:3063-3072.

Ye P, Li L, Richards RG, DiAugustine RP, D'Ercole AJ (2002) Myelination is altered in insulin-like growth factor-I null mutant mice. J Neurosci 22:6041-6051.

Yong VW (2005) Metalloproteinases: mediators of pathology and regeneration in the CNS. Nat Rev Neurosci 6:931-944.

Yong VW, Power C, Forsyth P, Edwards DR (2001) Metalloproteinases in biology and pathology of the nervous system. Nat Rev Neurosci 2:502-511. 